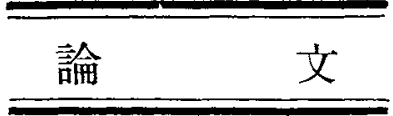

\title{
$13 \mathrm{Cr}$ ステンレス鋼のオーステナイト化状態术び 変態挙動におよ深す炭化物溶解の意義
}

中 沢 一 雄 ${ }^{* *}$

Kazuo Nakazawa: Effect of Carbide Dissolution on the Austenitization and the Behavior in Transformation of $13 \mathrm{Cr}$ Stainless Steel. On three samples of $13 \mathrm{Cr}$ stainless steel containing $13 \%$ of chromium and $0.09 \%, 0.17 \%$ and $0.26 \%$ of carbon, the effect of austenitizing temperature on the Ms and Mf points and on the microstructure has been investigated and the TTT-diagrams have been established at the different austenitizing temperatures for 10 minutes in order to investigate the correlation between the austenitization and the behavior in transformation. The Ms and Mf points were measured by the dilatometric method and the process of isothermal transformation was examined by the use of hardness and microscopic tests. The Ms and Mf points become evidently lowered by dissolution of the carbide. In the pearlite transformation, the higher the austenitizing temperature rises, the longer grows the incubation period and the slower the transforming rate. Comparison of the Ms and Mf points and the TT'T-diagrams of the three samples revealed the difference coming from the influence of their chemical compositions on the transformation process. These results may illustrate the dependence of the behavior in transformation mainly on the concentrations of carbon and chromium.

(Received July 19, 1961)

\section{I. 緒 䨐}

当実験は炭素量異なる 3 つ実用 $13 \mathrm{Cr}$ ステンレス鋼炕 つき，その変態点以上への加熱に際して焼入温度、または 最高加熱温度の影響に関連した事項として，炭化物および フェライトのみーステナイト中への溶解状況，およびオー ステナイト化状態の変化を検討し，そしてそれらの違いが マルテンサイト変態および恒温变態の経過にどのように反 坱するかを調査したもので，炭化物などの異相溶解に基ら くオーステナイトの組成变化代対応して，溶蟹成分元素の 変態挙動に扰よぼす影響をチェックするととるに，この鋼 の熱処理燈する事項について一つの認識を得るために行 つた実験である。

\section{II. 実 験 方 法}

試料として，その化学組成は Table 1 の如き実用 $13 \mathrm{Cr}$ ステンレス鍓一種 (SUS 1), 二種(SUS 2), 三種 (SUS 3) の

Table 1 Chemical composition of steels, $\%$.

\begin{tabular}{l|c|c|c|c|c|c|c|c}
\hline Mark & $\mathrm{C}$ & $\mathrm{Si}$ & $\mathrm{Mn}$ & $\mathrm{P}$ & $\mathrm{S}$ & $\mathrm{Cr}$ & $\mathrm{Ni}$ & $\mathrm{N}$ \\
\hline SUS 1 & 0.09 & 0.14 & 0.18 & 0.026 & 0.007 & 13.74 & 0.42 & 0.0206 \\
SUS 2 & 0.17 & 0.46 & 0.74 & 0.028 & 0.007 & 13.29 & 0.06 & 0.0177 \\
SUS 3 & 0.26 & 0.57 & 0.63 & 0.024 & 0.018 & 12.97 & 0.14 & 0.0272 \\
\hline
\end{tabular}

正延棒材を用いた楛鈍材より検鏡，硬度試験用として 10 $\mathrm{mm} \phi \times 3 \mathrm{~mm}$ の小試片および $5 \mathrm{~mm} \phi \times 80 \mathrm{~mm}$ の熱膨張計

** 岩手大学工学部金属工学科 (Department of Metallurgy, Faculty of Engineering Iwate University, Morioka)

* 1959 年 4 月本会東京大会比発表
用試片を切りとつた。変態点以上の备オーステナイト化温 度への加熱はすべて加熱速度 $15^{\circ} \mathrm{C} / \mathrm{min}, 10 \mathrm{~min}$ 間保持と した，酸化防止のため試料佐藤氏塗料(1)(2)を塗有して 大気中にて加熱した・マルテンサイト变熊の経過は抎大率 2600 倍の熱膨張計にて測定した，すなわり試片をオーステ ナイト化加熱後 $450^{\circ} \mathrm{C}$ の鉛浴中に投中し，後これを予め同 温度に保つてある熱膨張計に早く取りつけ, オーステナイ ト安定領域からマルテンサイト変態頜域を徐冷して测定し た．TTT-曲線は硬度試験（ビッカース，30 kg）上袷鏡に よつて決定した。

\section{III. 実 験 結 果および考察}

\section{1. 温度によるオーステナィト化} 状龍の変化

従来出されている $\mathrm{Fe}$-Cr-C 系状態図(3) を基準として, 大体推定した $13 \%$ Cr の切断図は Fig. 1 の如くである. 実験的に得られた 各变態点は Table 2 の如くであつて, $\mathrm{Ac}_{1}$ 領域については大体 Fig. 1 と一致するが $\mathrm{Ac}_{1}$ 以上に 拈いては $\mathrm{Ac}_{3}$ 就よひ $\mathrm{Ac}_{\varepsilon}$ はいつれる高く出万上に，この 關共存相の存在状況比ついて異なるものがあり, 平衡状 態図的表現からはかけ離れたものであつた。

Photo. 1 は备試精を各温度に加熱後水冷したものにつ いての顕微鏡組織の一例である. SUS 1 では $\mathrm{AC}_{1}$ 点直上の 温度に扎いて， $\gamma$ と 40〜50\%のフェライトと微粒の炭化 物の三つが存在する，温度の上异ととるに一部のフェライ

(1) 佐藤：金属の研究，2(1925)，63.

(2) 近藤: 本誌, 7(1943), 193 .

（3）村上：金属の研究，8(1931)，341. 
トと炭化物が $\gamma$ 中に溶け込み, $1030^{\circ} \mathrm{C}$ 以上飞括いて均等 なとの地と約 $30 \%$ のフェライトが共存する.フェライト

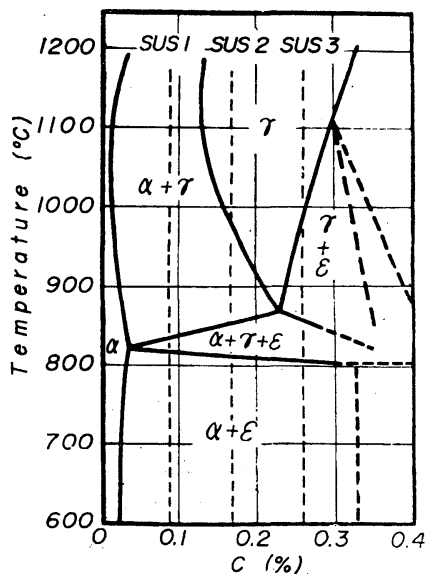

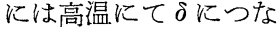
がる大きな粒の遊離フ ェライトと共析の地に 細長く入込んだものと ある，そして変態点以 上に扣いて溶け込む のはこの細長いフェラ イトである，このフェ ライトの出入は $A_{3}$ 線 に沿与変化と思われ る. SUS 2 では $A c_{1}$ 点 以上:たおいて, SUS 1 と同様 $\gamma$ ともにフェ

Fig.1 $13 \%$ Cr sectional diagram, ライトと炭化物が存在 infered approximately from the previous data in refer-するが, 温度の上䄯と ence to the Fe-Cr-C diagram. ともに両者は $\gamma$ 中に溶

Table 2 Transformation points decided experimentally for the steels used.

\begin{tabular}{l|c|c|c}
\hline Mark & $\mathrm{Ar}_{1}$ & $\mathrm{Ac}_{1}$ & $\mathrm{Ac}_{3}$ or $A \mathrm{c}_{\varepsilon}$ (about) \\
\hline SUS 1 & $675^{\prime} \sim 730^{\prime}$ & $820^{\prime} \sim 875^{\prime}$ & $\left(1030^{\prime}-10 \mathrm{~min}\right)$ \\
SUS 2 & $675^{\prime} \sim 760^{\prime}$ & $830^{\prime} \sim 895^{\prime}$ & $1040^{\prime}-10 \mathrm{~min}$ \\
SUS 3 & $665^{\prime} \sim 730^{\prime}$ & $805^{\prime} \sim 860^{\prime}$ & $1050^{\prime}-10 \mathrm{~min}$ \\
\hline
\end{tabular}

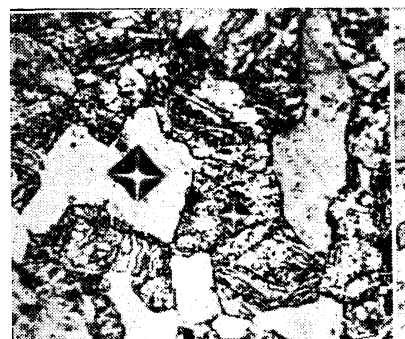

(a) SUS $1-900^{\prime} \mathrm{C}$

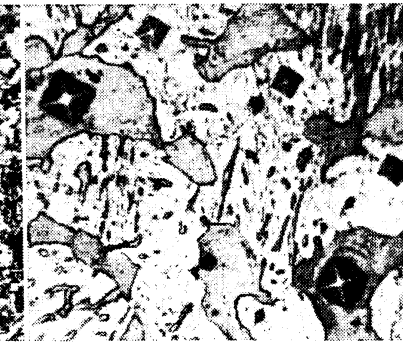

(b) SUS $1-1000^{\prime} \mathrm{C}$

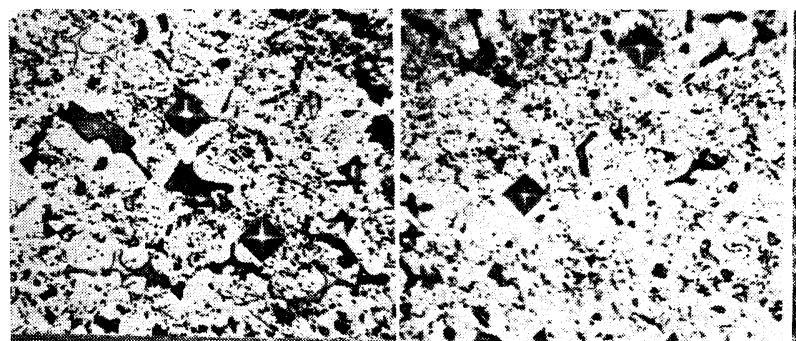

(d). SUS $2-900^{\prime} \mathrm{C}$

(e) SUS $2-950$ 'C
Fig. 2 は上記の検鏡試糊につき，組織成分別の微小硬度 を測定し，遊離フェライトと区別してマルテンサイト基地

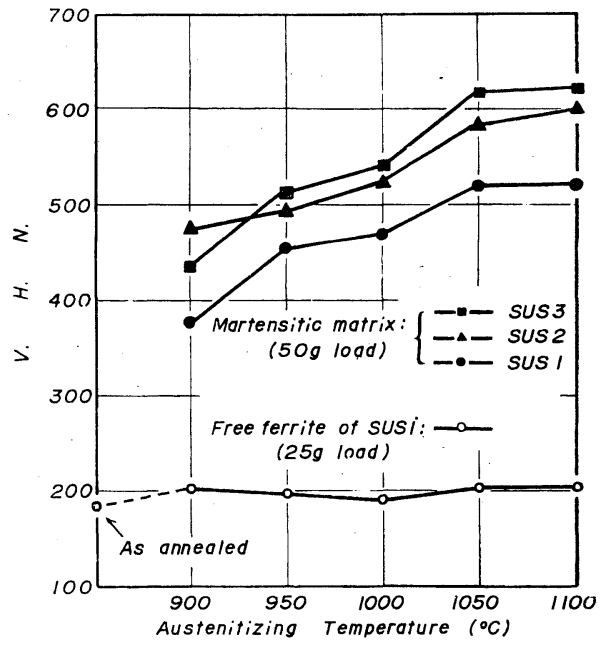

Fig.2 Microhardness of microconstituents of steels SUS 1, SUS 2 and SUS 3 after water cooling from various austenitizing temperatures for 10 minutes.

の㯰度変化を見たものである. SUS 1 については遊離フェ ライトの硬度も測定した，硬度㑤は 5〜10回の雨均をとつ た.

Fig. 3 は各加熱温度に対するオーステナイト粒度，Ms 扣よび Mf 点の変化を示すものである.Ms, Mf 点の変化は 炭化物またはフェライトの溶解によるオーステナイト中の

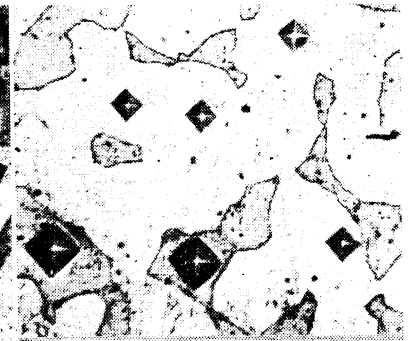

(c) SUS $1-1050^{\prime} \mathrm{C}$
$\mathrm{C}, \mathrm{Cr}$ 量の変化を反映 しているものと思われ る.ここで炭化物の溶 解は C, Cr の濃度の堌 大をもたらし，フェラ イトの溶解はC湍度を 低めるが Cr 濃度を増 すものと考えられる。 SUS 2, SUS 3 の $1100^{\circ}$ C-10 min の場合は之 もに未溶解異相はな

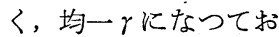
り, 両者間にはC含有 量の違いがあるだけで ある.この場合の両者 の Ms 值の差異から算 (f) SUS 3-950' C

Photo.1 Microstructures of steels SUS 1, SUS 2 and SUS 3 after water cooling from the various austenitizing temperatures for 10 minutes, with microhardness indentations. Curran's reagent. $(\times 390)$

出すると, $\operatorname{Cr} 13 \%$ の 場合として，C $0.1 \%$ の増加は Ms 点を 75

解し, 約 $1040^{\circ} \mathrm{C}$ で全部溶け込み $\gamma 1$ 相となる. SUS 3 に 扣いては $\mathrm{Ac}_{1}$ 点以上で $\gamma$ と炭化物の 2 相が存在し, 温度 の上年とともに炭化物が溶解し，約 $1050^{\circ} \mathrm{C}$ で $\gamma 1$ 相にな る. 当鋼の炭化物は $\varepsilon$ 相と呼ばれる Cr の特殊炭化物で ある。
${ }^{\circ} \mathrm{C}$ 降下させることになる，Payson 拉よび Savage(4) によ ると, C $0.5 \%$ 一定の場合には Cr $1 \%$ の増加は Ms 点を $28^{\circ} \mathrm{C}$ 降下させる。

(4) P. Payson and C.H. Savage : Trans. ASM, 33 (1944) ,261. 
Ms 点は熱膨張曲楾の極小点, また Mf 点は極大点につ いて決定したものであるが，各曲線の経過を此較して見る

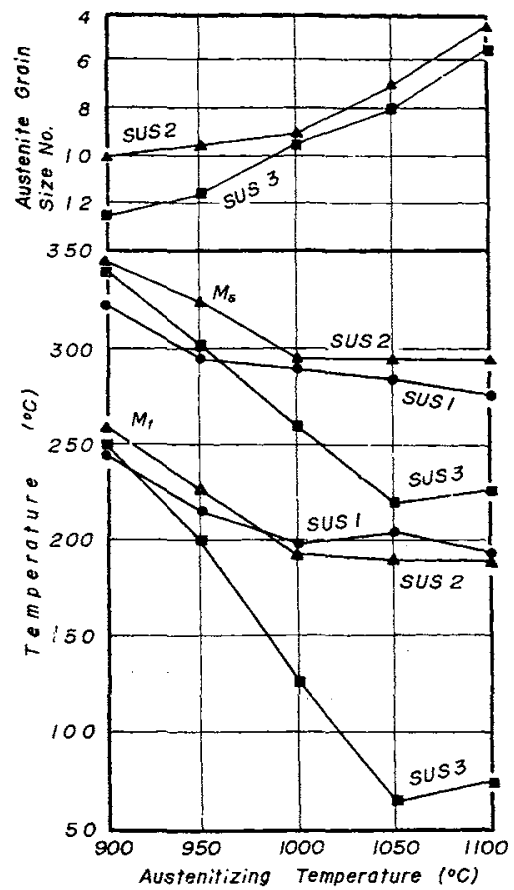

Fig.3 Effect of austenitizing; temperature on the austenite grain size and the Ms and Mf points in steels SUS 1 , SUS 2 and SUS 3. Austenitizing time is each 10 minutes.

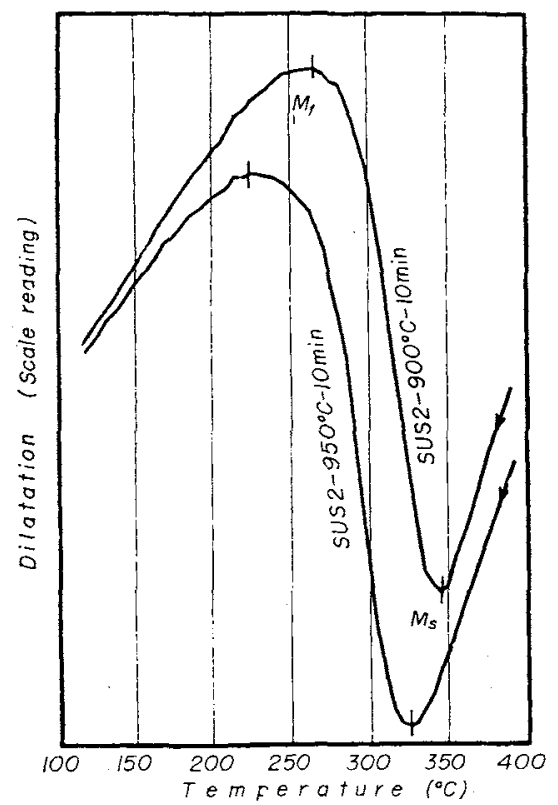

Fig.4 Dilatation curves of steel SUS 2 during martensite transformation.

と，その形状に幾らかの違いが出ている。一例として Fig. 4 はSUS 2についての曲線を比較したものである.オース テナイト中に炭化物の溶解が進行中と思われる段階に扣い ては，梪小点より低温側に，また低孷素部分が存在すると 思われる段階に搔いては，極小点の右㒋にそれぞれ多少の
凹凹が出て来る、これらの曲線形状の変化はオーステナイ ト中の溶解成分濃度の均一性と関係があるものと考えられ

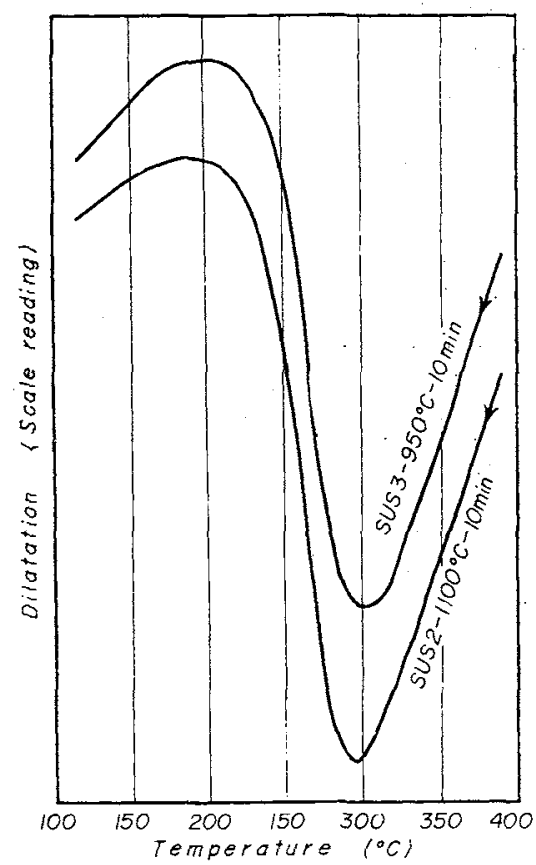

Fig. 5 Dilatation curves of steels SUS 2 and SUS 3 during martensite transformation.

ている(5)(6).

Fig. 5 は SUS 2 の $1100^{\circ} \mathrm{C}-10 \mathrm{~min}$, SUS 3 の $950^{\circ} \mathrm{C}-10$

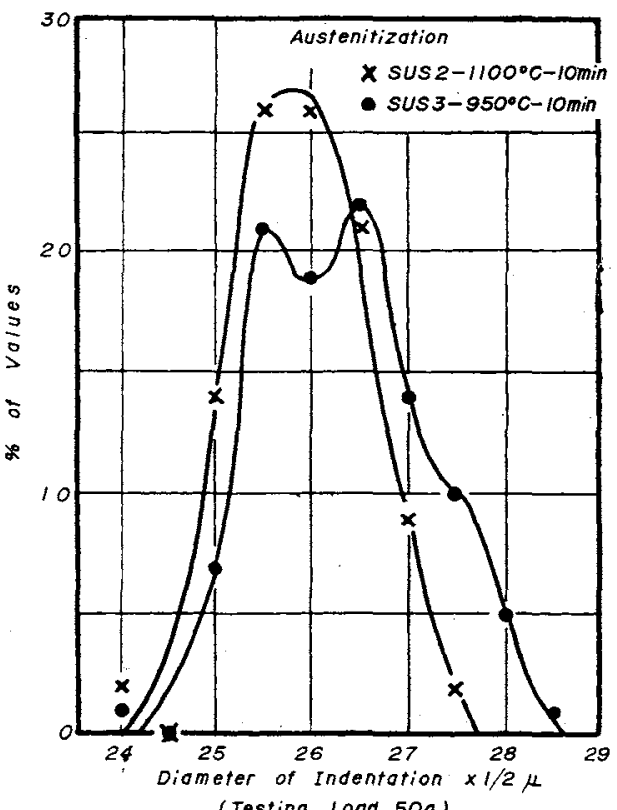

(Testing Lood 509)

Fig.6 Distribution of microhardness values of martensitic structure as measured for the dilatometer specimens after measurement of dilatation change in Fig. 5 .

(5) A. Rose und L. Rademacher: Stahl u.Eisen, 77 (1957), 409.

(6) F. Wever: 鉄乞鋼, 45(1959), 136 . 
$\min$ オーステナイト化の場合のマルテンサイト変態の熱膨 張曲線である.Fig. 6 は Fig. 5 に用いた試験片につき， その測定後に微小硬度を 100 回测定し，その分散の状況を 出し, Fig. 5 の曲線形状と対照比較したものである.この マルテンサイト組織の微小硬度值の分散度は母体オーステ ナイトの溶解成分濃度の均一度と関係があるものと思われ る(5)(6).

\section{2. 恒温変態におよぼすオーステ ナイト化温度の影響}

Fig. 7, Fig. 8, Fig. 9 はそれぞれ各鋼の $950^{\circ} \mathrm{C}-10$ min および $1050^{\circ} \mathrm{C}-10 \mathrm{~min}$ オーステナイト化の場合の二つの TTT-曲線を示している。まず 3 者を通じての比校とし て, $1050^{\circ} \mathrm{C}-10 \mathrm{~min}$ の場合のパーライトノーズのPSは SUS 1 が最も早くSUS 3 が最も遅い，これはC 含有皆ひ 影響と考えられる. $950^{\circ} \mathrm{C}-10 \mathrm{~min} の$ 場合はれーステナイ ト中の C 量は硬度值からして, SUS 1 が羁小で SUS 3 が 最大と考えられるが，PS SUS 2 が最も早くSUS 1 が中 間となつている。これは炭化物溶解が末だ充分でない状態 において, SUS 1 の $0.42 \%$ Ni の影響が忙て来たすの と考えられる、Fig.3の Ms 点変化において SUS 1 の值が SUS 2 のそれを下廻つているのもこのためと栲えられる.

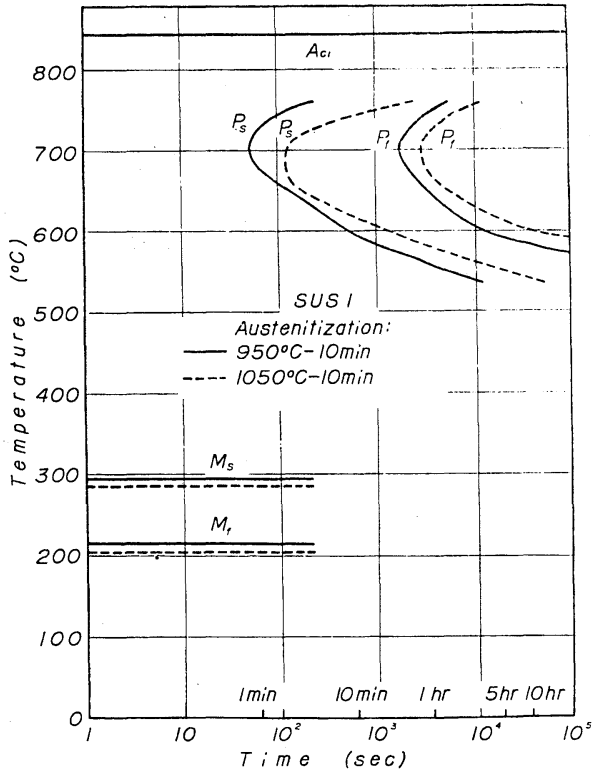

Fig.7 TTT-diagrams of steel SUS 1 for the two different austenitizations.

ノーズに拈け Pf-Psについては, $1050^{\circ} \mathrm{C}, 950^{\circ} \mathrm{C}$ の場合 共に, SUS 1 が最も長くSUS 3 が最も短い, これはオー ステナイト中の C 含有量と関連して，Cの拡散の距離に関 係しているものと考えられる。

各鋼共オーステナイト化温度の上昇とともに，Ps は遅 くなり, Pf-Ps は長くなる, 前者の変化は主としてオース テナイト中の C 含有量の変化によるものであり, 後者につ いてはオーステナイト粒度の影響も考えられるが，この際 は主としてオーステナイト中の Cr 含有量の変化によるも
のと考えられる。な抬参考のために $\mathrm{N}$ 量を揭げたが， Nは パーライトノーズの潜伏期を大にするといわれている(7).

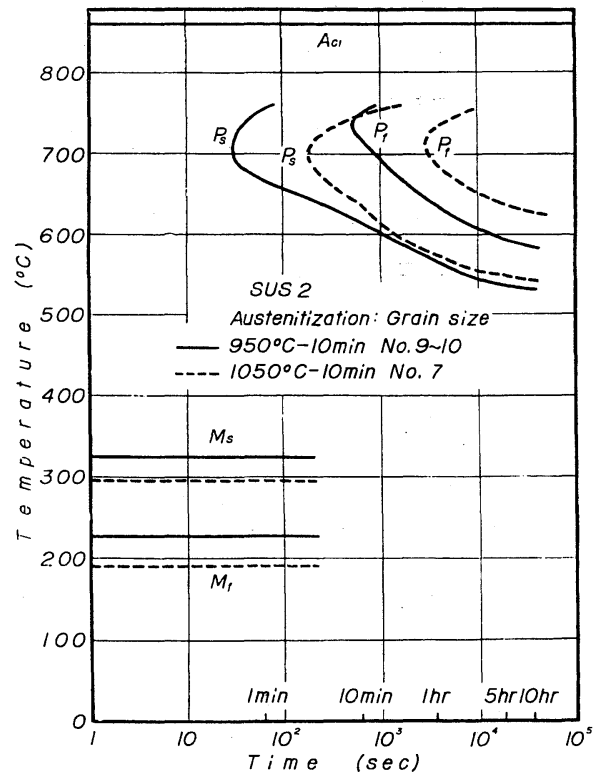

Fin.8 TTT-diagrams of steel SUS 2 for the two different austenitizations.

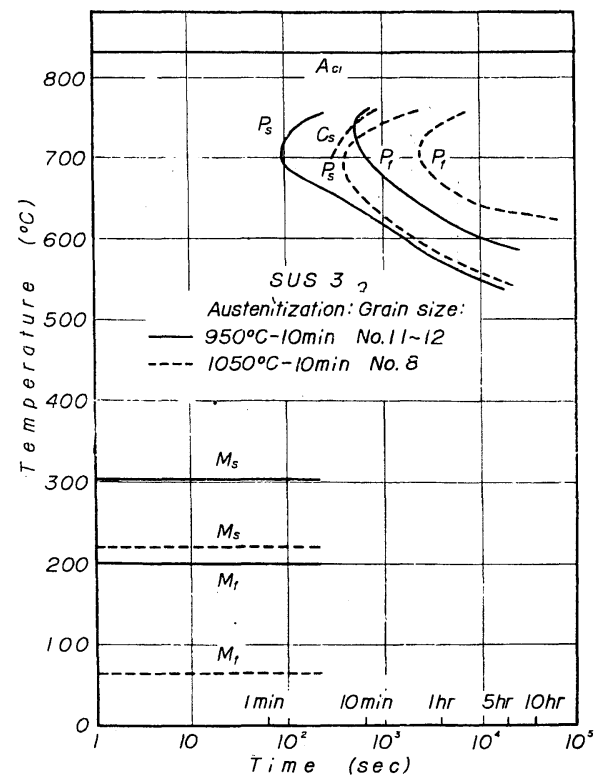

Fig.9 TTT-diagrams of steel SUS 3 for the two different austenitizations.

Photo. 2 は各鋼の変態途中の組織である.パーライト変 態について特徵的なことは, Photo. 2 (c), (g) の如くに粒 界扣よび粒内に扣いて炭化物の析出が起ると, それを包む ある領域がフェライトになつて变態が進行するようであ る. 変態温度が低下するにつれて, 粒界近傍から粒内に向 つての析出の進行が遅くなり, さらに粒界にも変態物がで きにくくなり $500^{\circ} \mathrm{C}$ 以下汸持いては変態は起らない. SUS

（7）岡本, 内藤：本誌，24(1960),633, 
1 に扰いてはP Photo.2 (a)，(b) の如くに変態物は遊離〉ェ ライトとの粒界に優先的に出て来る, そして炭化物の析出
結果から, 異相溶解に伴らオーステナイト化状態の变化に 関連して, 成分元素の変態挙動におよぼす影響はつぎの如

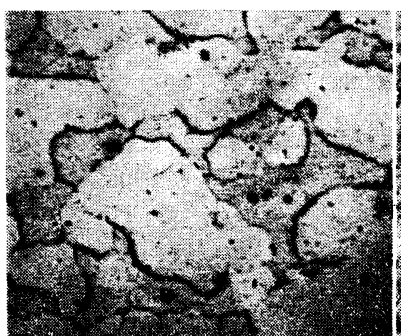

(a) SUS $1-1050^{\prime} \mathrm{C}$ $700^{\prime} \mathrm{C}-3 \mathrm{~min}$

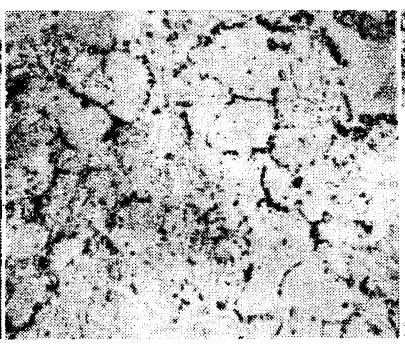

(b) SUS $1-950^{\prime} \mathrm{C}-$ $700^{\prime} \mathrm{C}-3 \mathrm{~min}$

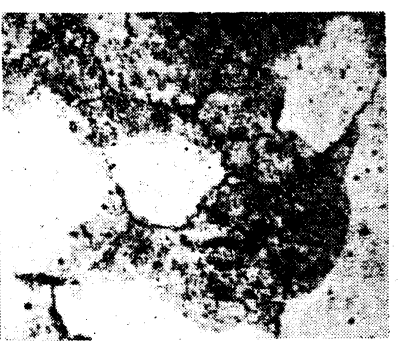

(c) SUS $2-1050^{\prime} \mathrm{C}$ $750^{\prime} \mathrm{C}-40 \mathrm{~min}$

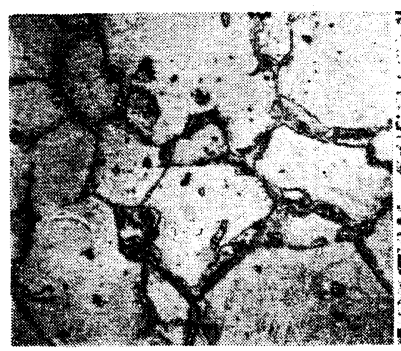

(d) SUS 2-1050'C$650^{\prime} \mathrm{C}-30 \mathrm{~min}$

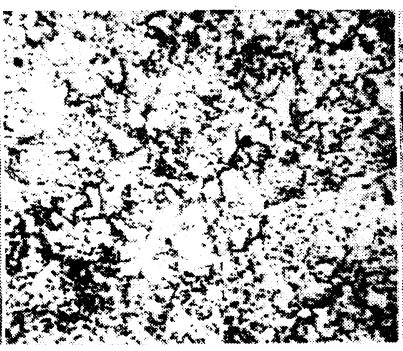

(e) SUS $2-950^{\prime} \mathrm{C}$ $750^{\prime} \mathrm{C}-15 \mathrm{~min}$

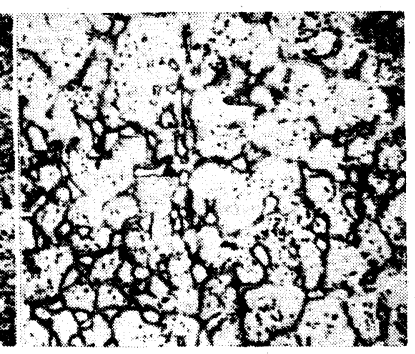

(f) SUS $2-950^{\prime} \mathrm{C}$ $600^{\prime} \mathrm{C}-90 \mathrm{~min}$

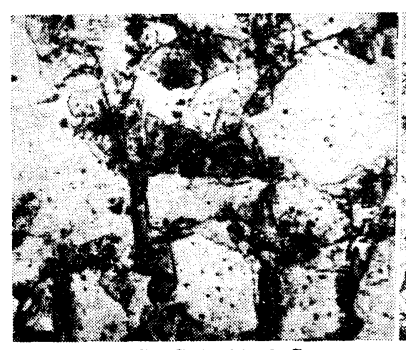

(g) SUS $3-1050^{\prime} \mathrm{C}-$ $700^{\prime} \mathrm{C}-20 \mathrm{~min}$

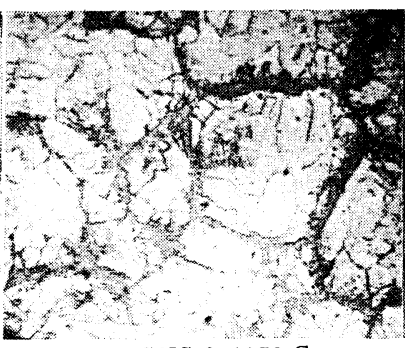

(h) SUS $3-1050^{\prime} \mathrm{C}$ $650^{\prime} \mathrm{C}-2 \mathrm{hrs}$

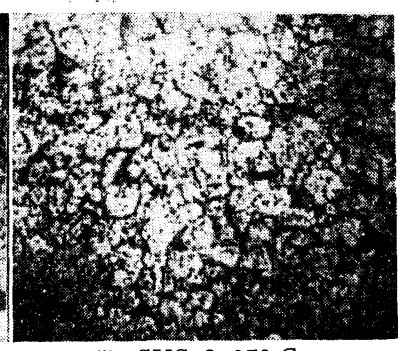

(i) SUS $3-950^{\prime} \mathrm{C}$ $650^{\prime} \mathrm{C}-30 \mathrm{~min}$

Photo.2 Microstructures of steels SUS 1, SUS 2 and SUS 3 isothermally transformed. Curran's reagent. $(\times 360)$

はその粒界に片寄る傾向があるようである(8).

IV. 総括

C. $0.09,0.17,0.26 \%$ をそれぞれ含有する三つの $13 \mathrm{Cr}$ ステンレス鋼につき，相異なるオーステナイト化温度につ いて, Ms, Mf 点扣よび TTT-曲線を求めた。そしてその （8）作井，森，山本：鉄と鋼， 45 (1959)，117.
くに要約される.

(1) 炭化物の溶解によって Ms 点は降下する, そして Cr $13 \%$ 一定とすると，C $0.1 \%$ の增加は Ms 点を $75^{\circ} \mathrm{C}$ 降下させる。

（2）TTT-曲線上においては，Cの增加はPSを遅らせ， Pf-Ps を短くし，また Cr の増加はPf-Psを長くするもの と考えられる. 